\title{
STEROID INHALATION VERSUS SURGERY IN TREATMENT OF POST-INTUBATION GRANULOMA
}

Wael A. Alzamil, M.D.* and Essam Fathy, M.D. Hearing and Speech Institute, * Sameer Attya, M.D. Banha teaching hospitals *MOHAMMED ELSHABBOURY ,MD. Shebin Elkom teaching hospitals, General Organization for Teaching Hospitals and Institutes, Egypt

\section{ABSTRACT}

We are aiming from our study to compare the results of vocal process granulomas treated with inhaled steroids and surgical treatment. Intubation granuloma of the larynx is induced by endotracheal intubation, mainly managed by conservative medical treatment with observation. If no response to medical treatment surgical excision can be considered as a last line of treatment due to the reported recurrence with subsequent repeated surgeries and exposure to anesthesia. 30 granulomas were diagnosed in 24 patients: 6 bilateral and 18 unilateral. 15 granulomas in 12 patients in group A were treated with Steroid inhalation. $1(6.6 \%)$ did not respond, 4 (26.6\%) partially responded, and 10 (66.6\%) completely responded, No cases had recurrence. In group B which treated surgically, of the 15 granulomas, 15 (100\%) removed completely by micro laryngeal cold instruments. Partial recurrence occurred in 2 patients unilateral after 10 weeks $13.3 \%$. Considerable recurrence has been developed in 3 more patients (unilateral) beside the first 2 granulomas (5 Granulomas) $33.3 \%$ recurrence after 50 weeks follow up. We advise to manage intubation granuloma of the larynx mainly by inhaled steroid as a first line of treatment.

Key Words: Dysphonia - Intubation granuloma - Steroid inhalation-surgery.

Corresponding author:

Received: 1 October 2015

Essam Fathy

Accepted: 28 October 2015

\section{INTRODUCTION}

I ntubation granuloma is one of the chronic changes after extubation, representing one of the most common lesions in the spectrum of intubation injuries ${ }^{[1,17]}$.

When mucosal healing is incomplete and perichondritis persists, granulation tissue remains as a chronic, localized, rounded, intubation granuloma, usually unilateral but sometimes bilateral $^{[5]}$.

Granulomas occur at the common site of ulceration arising from the vocal process and medial surface of the arytenoid where the mucoperichondrium attaches directly to the cartilage ${ }^{[\mathbf{8 , 9 , 1 0 , 1 1 ]}}$.

Granulomas in atypical sites, such as the sub glottis or the anterior larynx are probably caused by a laceration from the tip of the endotracheal tube or by the introducer projecting from the tube. The patient with an intubation granuloma presents days, weeks, or months after intubation with dysphonia, a feeling of "something there," or noisy breathing from airway obstruction if the mass is very large ${ }^{[20]}$.

Intubation granulomas can be removed using the carbon dioxide laser, but potential irritation by the carbon chart makes necessary to remove it ${ }^{[6,7]}$.
Cold microlaryngeal surgery using forceps and scissors causes bleeding making it difficult to identify the attachment of the mass in some cases ${ }^{[13]}$.

Accurate removal is important, under removal allows the remainder to proliferate into a recurrent granuloma, whereas too deep removal exposes the cartilage and peichondrium of the vocal process, again predisposing to recurrence. So ,Conservative nonsurgical removal of granulomas (medical excision) by steroid inhalation avoid these surgical problems of recurrence or residual pathology ${ }^{[16]}$.

We sought to compare the outcomes of vocal process granulomas treated with inhaled beclomethasone and surgical treatment.

\section{PATIENTS AND METHODS}

\section{Studied patients:}

Among the patients with intubation granuloma of the larynx who presented to the ENT clinic in the 6 years between April 2009 and April 2014 . gave written, informed consent to participate in the study. 24 patients of intubation granuloma were 6 bilateral and 18 unilateral (30 granulomas). Patients were subjected to detailed history and thorough physical examination. Flexible and rigid laryngoscopy were documented by photos and video recording. All of the granulomas were 
located on the vocal process of the the arytenoid cartilage. 18 patients $(75 \%)$ were females, All patients were devoid of any neurologic or psychiatric disorders, and none of them was taking any long-term medications.

\section{Treatment protocol:}

All patients were devided into two groups (A and B ) each group consists of 12 patients 3 bilateral and 9 unilateral granulomas .All of the subjects of group A treated by beclomethasone dispropionate inhalation per day e.g. BECLAZONE (300 ug 3 times a day). Patients were started on a 6to-8-week trial, with further medical therapy based on repeated examination. follow-up evaluations took place every 6 to 12 weeks until recovery. failure of treatment was defined as no improvement in signs or symptoms following 2 courses of treatment. Time to partial recovery, time to complete recovery ,and time of treatment were measured in weeks .completion of treatment was defined as completion of at least one (6to 8-weeks) course of medical therapy with follow up. Resolution of vocal process granulomas was determined by modification of the grading system of Emami et al(6).cases with complete resolution of symptoms and no identifiable lesion were defined as completely resolved. cases with discoloration, including erythema, without lesion were defined as completely resolved, cases that had improvement in symptoms, as well as a reduction in the size of the granuloma, and any lingering lesion, including ulceration, were defined as partially resolved. Cases that demonstrated no symptomatic improvement or a worsening of symptoms were defined as non-responsive to treatment. Group B treated surgically by direct laryngoscopy and cold microlaryngeal surgery ,no corticosteroid therapy or laser.

Inclusion criteria: Intubation granuloma occurs in patients who have history of recent intubation(less than 2 months)for general anesthesia.

Exclusion criteria: patients with laryngeal malignancy, other benign lesion of vocal fold, short follow up period were excluded

\section{Statistical analysis:}

The statistical analysis included the arithmetic mean, standard deviation (SD), standard error, hypothesis Student's "t", and Pearson's correlation tests.

\section{RESULTS}

A total of 24 patients with diagnosis of post intubation granuloma between 2009 and 2014 were reviewed. among them, there were 6 males and 18 females. Median patient age at time of the initial examination was 27.7 years, with a range from 18 to 40 years, Table 2 and 3.

Their symptoms including hoarseness in 19 patients $(79.1 \%)$, cough in 6 patients (25\%), foreign body sensation in the throat in 3 patients $(12.5 \%)$ table 1. six patients $(25 \%)$ presented by bilateral granuloma, and 18 patients $(75 \%)$ had unilateral granuloma. Fifteen patients $(62.5 \%)$ had left sided lesion, 3 patients ( $12.5 \%)$ had right sided lesion and 6 patients $(25 \%)$ had bilateral lesion, table 2 and 3.

Results In group A are shown in Table (2), 15 granulomas in 12 patients in group A were treated with Beclomethasone (BECLAZONE) inhalation. Of the 15 granulomas that completed treatment, 1 (6.6\%) did not respond (time of follow-up, 39 weeks), 3 (25\%) partially responded (mean follow-up, 57.6 weeks; range, 43 to 75 weeks), and 8 (66.6\%) completely responded (mean follow-up, 56.8 weeks; range, 30 to 78 weeks). No cases had recurrence

Results In group B are shown in Table (3), In this group (B) which treated surgically, of the 15 granulomas, $15(100 \%)$ removed completely by micro laryngeal cold instruments (mean follow-up, 21.4 weeks; range, 12 to 30 weeks). Partial recurrence occurred in 2 patient unilateral after 10 weeks 16.6.\%Considerable recurrence has been developed in 3 more patients (unilateral) beside the first 2 granulomas ( 5 Granulomas ) $33.3 \%$ recurrence after 30 weeks follow up. No anesthetic or surgical complications occurred in group B .

The follow up period was noticed to have a different effect on the outcome in both groups. In group A , it have direct relationship with the outcome which improves progressively with more weeks of steroid 
inhalation and follow up fig 1 . In group B, there is a reverse relationship with the outcome which presents more recurrences with more weeks of follow up

Table1:presentation of symptoms.

\begin{tabular}{|l|l|l|}
\hline \multirow{2}{*}{ Symptoms } & \multicolumn{2}{c|}{ Patients } \\
\cline { 2 - 3 } & No. & \multicolumn{1}{c|}{$\%$} \\
\hline Hoarseness & 19 & 79.1 \\
\hline Cough & 6 & 25 \\
\hline Sore throat & 7 & 29.1 \\
\hline F.B. sensation & 3 & 12.5 \\
\hline Dysphagia & 2 & 8.3 \\
\hline Sensation of increased mucous & 2 & 8.3 \\
\hline Ear pain & 2 & 8.3 \\
\hline Vocal fatigue & 1 & 4.1 \\
\hline Hemoptysis & 1 & 4.1 \\
\hline
\end{tabular}
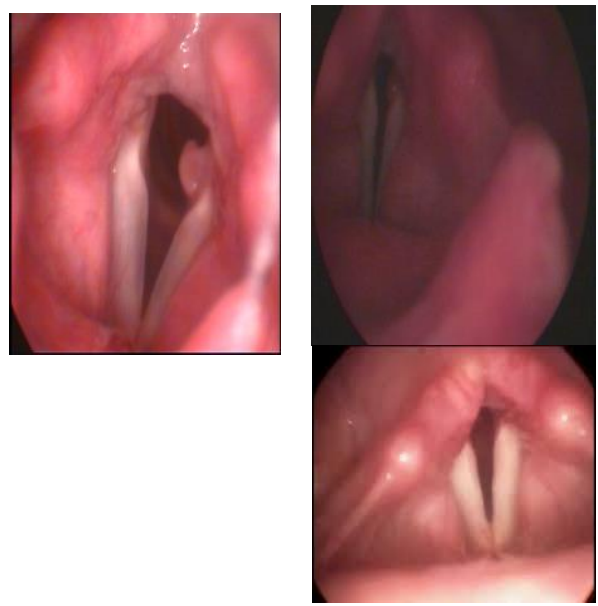

Fig.1 intubation granuloma under steroid inhalation therapy case number 6

Table (2): clinial characteristics and therapeutic results of beclomethasone dispropionate inhalation

\begin{tabular}{llllllll}
\hline $\begin{array}{l}\text { Patien } \\
\mathrm{t} \text { no. }\end{array}$ & $\begin{array}{l}\text { Ag } \\
\mathrm{e}\end{array}$ & Sex & Chief complaint & Site & $\begin{array}{l}\text { Time of } \\
\text { follow-up }\end{array}$ & Response & Rec. \\
\hline 1 & 18 & Female & Hoarseness & Bilat. & 55 & partial & - \\
\hline 2 & 30 & Female & Cough ,hoarseness & Left & 60 & complete & - \\
\hline 3 & 22 & Male & Hoarseness & Left & 43 & partial & - \\
\hline 4 & 19 & Female & Cough, hoarseness & Left & 30 & Complete & - \\
\hline 5 & 31 & female & Sore throat, & Right & 39 & No response & - \\
& & & Hoarseness & & & & \\
\hline 6 & 35 & Female & F.B. sensation & Left & 42 & complete & - \\
\hline 7 & 28 & Male & Hoarseness & Left & 47 & Complete & - \\
\hline 8 & 33 & Female & Cough, hoarseness & Bilat. & 70 & Complete & - \\
\hline 9 & 25 & Female & Sore throat,hoarseness & Left & 75 & Partial & - \\
\hline 10 & 26 & Female & Sore throat,ear pain & Left & 78 & Complete & - \\
\hline 11 & 36 & Female & Hoarseness & Bilat. & 69 & Complete & - \\
\hline 12 & 29 & Female & Hoarseness & Bilat. & 59 & Complete & - \\
\hline
\end{tabular}


Table (3): clinial characteristics and results of cold micro laryngeal surgery (group B).

\begin{tabular}{cccccccc}
\hline $\begin{array}{c}\text { Pat } \\
\text { no } \\
\cdot\end{array}$ & $\begin{array}{c}\mathrm{Ag} \\
\mathrm{e}\end{array}$ & Sex & Chief complaint & Site & $\begin{array}{c}\text { Time } \\
\text { of } \\
\text { follo } \\
\text { w-up }\end{array}$ & Response & Rec. \\
\hline 1 & 19 & Female & Hoarseness & Left & 25 & Complete & No \\
\hline 2 & 25 & Female & Cough, Hoarseness & Bil. & 22 & Complete & Partial (6weeks) \\
\hline 3 & 24 & Female & $\begin{array}{c}\text { Hoarseness, Globus } \\
\text { sensation }\end{array}$ & Left & 12 & Complete & Considerable (22weeks) \\
\hline 4 & 40 & Female & Hoarseness & Right & 14 & Complete & No \\
\hline 5 & 32 & Male & Globus sensation & Left & 29 & Complete & No \\
\hline 6 & 23 & Female & Cough & Right & 26 & Complete & No \\
\hline 7 & 21 & Female & Hoarseness & Left & 14 & Complete & Considerable (27 weeks) \\
\hline 8 & 32 & Male & Hoarseness, ear & Left & 18 & Complete & No \\
\hline 9 & 29 & Female & Hoarseness & Left & 29 & Complete & Partial (10weeks) \\
\hline 10 & 34 & Male & Hoarseness & Left & 30 & Complete & No \\
\hline 11 & 26 & Female & Cough, & Bil. & 12 & Complete & Considerable (21 weeks) \\
& & & F.B.sensation & & & & \\
\hline 12 & 28 & Female & Hoarsens & Left & 26 & Comple & No
\end{tabular}

\begin{tabular}{llllcccc}
\hline 12 & 28 & Female & Hoarseness & Left & 26 & Complete & No \\
\hline & & & necrosis of the vocal process area. The
\end{tabular}

\section{DISCUSSION}

The epidemiology, presentation, and causes of intubation granuloma in this study substantiate previous published results. ${ }^{[1,4]}$.

A greater number of female were affected by vocal process granuloma (by 3:1).An association that supports previous reports that women are more likely to sustain vocal process granuloma from intubationrelated or surgical treatment, McFerran suggested that the thinner mucosa in smaller larynges makes women vulnerable to traumarelated granuloma ${ }^{[12,13]}$.

Hoarseness represent the most common presenting symptoms in all patients in our study, seen in $79.1 \%$ of patients ${ }^{[8,10]}$.

Higher incidence of left vocal cord affection than right side lesions $(9 ; p<0.001)$.this result is supported by other studies which show higher incidence of the left side than the right side, this phenomena could be related to intubation technique and tendency for right-handed placement of an endotracheal tube to cause the tube to come into contact with the left vocal process ${ }^{[9,15]}$.

Granuloma after intubation may occur because of direct abrasion of the arytenoid perichondrium, a break in the mucosa covering it as a result of coughing on an endotracheal tube, or long term pressure resulting reparative granuloma may initially progress from fairly sessile to large and pedunculated, but it may then regress entirely with maturation over several months ${ }^{[9,10]}$. Intubation granulomas can be removed using the carbon dioxide laser, but potential irritation by the carbon chart makes necessary to remove it. Cold microlaryngeal surgery using forceps and scissors causes bleeding making it difficult to identify the attachment of the mass. Accurate removal is important, under removal allows the remainder to proliferate into a recurrent granuloma, whereas too deep removal exposes the cartilage and peichondrium of the vocal process, again predisposing to recurrence. So, Conservative nonsurgical removal of granulomas (medical excision) by steroid inhalation avoid these surgical problems of recurrence or residual pathology ${ }^{[7,12,9]}$.

The failure of surgical excision may be explained by its failure to address the principle causes of vocal process granuloma.recurrenc rates following surgical excision similar to overall results ${ }^{[16,21]}$.

Inhaled steroids show the best results in reducing local inflammation. Budesonide, and Beclomethasone usually used to manage allergic rhinitis, asthma ,and nasal polyposis $^{[\mathbf{2 , 1 4}]}$.resolution of 19 of 20 intubation granuloma within 12 months by 
Roh et al ${ }^{[16]}$. the authors demonstrated resolution of 19 of 20 intubation granulomas within 12 months. 1999 Wang et al. : Compared treatment of intubation granuloma with/without inhaled steroid, more rapid regression of lesion was seen with steroid

Intubation granuloma show very high rates of resolution with inhaled steroids, our regimen applied the use of Beclomethasone because its greater effect as local antiinflammatory and has long term safety profile up to 12 months.if there is no or partial response we advise continuation of treatment for another 6 to 9 weeks. After improvement we allow gradual discontinuation of the inhaled steroids over the next 2 to 4 months $(\mathbf{2 , 3 )}$

\section{CONCLUSION}

In this study, recent vocal process postintubation granulomas respond to the antiinflammatory action of inhaled steroids successfully as with low rates of side effects and recurrence. Surgical excision of granulomas has good immediate relief of symptoms but has more recurrence rate and not without the risk of general anesthesia and surgical manipulation.

\section{REFERENCES}

1- Abbott TR : Complications of prolonged nasotracheal intubation in children, Br J Anaesth .1968 .347: 40

2- Allen DB. Effects of inhaled steroids on growth, bone metabolism and adrenal function .Adv pediatr .10-53:101;2006

3- Barnes NC ,Hallett C, Harris TA. Clinical experience with Fluticasone propionate in asthma: a meta-analysis of efficacy and systemic activity compared with budesonide and beclomethasone dipropionate at half the microgram dose or less . Respir Med .104-92:95 ; 1998

4- Blanc VF ,Tromblay NA: The Complications of Tracheal Intubation: a new classification with a review of the literature ,Anesth Analg ,53:202 .1974

5- Donnelly WH :Histopathology of endotracheal intubation: an autopsy study of 99 cases, Arch pathol.1969,88:511
6- Emami AJ, Morrison M ,Rammage 1, Bosch D. Treatment of laryngeal contact ulcers and granulomas: a 12 -years retrospective analysis. J Voice 1999.7-13:612;

7- Havas TE, Priestley J ,Lowinger DS. A management strategy for vocal process granulomas. Laryngoscope 1999.6-109:301;

8- Hoffman HT, Overholt T ,Karnell M, Mc Culloch TM, Vocal process granuloma. Head neck .74-23:1061; 2001

9- Holinger PH, Johnston KC. Contact ulcer of the larynx. J Am Med Assoc.5-172:511;1960

10- Jackson C. Contact ulcer of the larynx. Ann Otol Rhinol Laryngol.38-37:227;1928

11- Jackson C ,Jackson CL. Contact ulcer of the larynx. Arch Otolaryngol.15-22:1;1935

12- McFerran DJ, Abdullah V ,Gallimore AP, Pringle MB, Croft CB. Vocal process granulomata . JLrngol Otol.20-108:216;1994

13- Nasri S ,Sercarz JA, Mc Alpin T ,Berke GS. Treatment of vocal fold granuloma using botulinum toxin type A. Laryngoscope 1995.8-105:585;

14- Nelson HS, Kane RE, Petillo J, Banerji D. Long-term safety of non-chloroflourocarboncontaining triamcinolone acetonide inhalation aerosol in patients with asthma .Azmacort HFA Study Group. J Asthma 2000.52-37:145;

15- Peacher GM. Vocal therapy for contact ulcer of the larynx. A follow-up of 70 patients. Laryngoscope 1961.47-71:37;

16- Rob HJ ,Goh EK, Chon KM, Wang SG. Topical inhalation steroid) budisonide ,Pulmicort nasal) therapy in intubation granuloma. J Laryngol Otol.32-113:427;1999

17- Snow JC, Hirano $M$,Balough K. Postintubation granuloma of the larynx.Anesth analg .8-45:425;1966

18- Wani MK, Woodson GE. Laryngeal contact granuloma .Laryngoscpoe.93-109:1589;1000

19- Wenig BM, Heffner DK. Contact ulcers of the larynx. A reacquaintance with the pathology of an often under diagnosed entity. Arch Pathol Lab Med 1990.8-114:825;

20- Wolfe VI ,Ratusnik DL: Vocal symptomatology of postoperative dysphonia, Laryngoscope 91:635, 1981 .

21- Ylitalo $\mathbf{R}$,Lindestad PA. A retrospective study of contact granuloma. Laryngoscope 999-109:433; .6 